\title{
Efektivitas Environmental Learning Bagi Mahasiswa
}

\author{
${ }^{1}$ Widya Anjelia Tumewu, ${ }^{2}$ Ester Caroline Wowor, ${ }^{3}$ Milan Kisi Rogahang \\ 1,2,3 Jurusan Pendidikan Ilmu Pengetahuan Alam, FMIPA Universitas Negeri Manado \\ Email Korespondensi: widyaanjeliatumewu@unima.ac.id
}

\begin{abstract}
Abstrak. Lingkungan sebagai sumber belajar merupakan salah satu metode yang penting untuk diterapkan dalam pembelajaran. Hal ini dikarenakan masalah dalam lingkungan merupakan hal yang sangat berkaitan dengan kehidupan sehari-hari namun kepedulian untuk mencintai lingkungan masih kurang disadari. Salah satu metode pembelajaran yang dapat digunakan untuk menjadikan lingkungan sebagai sumber belajar adalah environmental learning. Penelitian ini bertujuan untuk mengetahui efektivitas environmental learning bagi mahasiswa. Metode penelitian yang digunakan yaitu metode penelitian kuantitatif. Data diperoleh melalui kuesioner yang dibagikan kepada mahasiswa Jurusan Pendidikan IPA Universitas Negeri Manado sebanyak 24 orang yang mengikuti pembelajaran dengan menggunakan environmental learning pada mata kuliah Biokimia. Data dalam penelitian ini diolah menggunakan perhitungan skala Likert. Hasil penelitian menunjukkan indeks tanggapan mahasiswa diperoleh pada interval $80 \%$ - 100\% yang artinya responden sangat setuju bahwa metode environmental learning efektif untuk memotivasi mahasiswa dalam belajar IPA.
\end{abstract}

\section{Kata kunci: Environmental learning}

Abstract. Environment as a learning resource is one important method to be applied in learning. This is because problems in the environment are very much related to everyday life, but the concern for loving the environment is still less realized. One of the learning methods that can be used to make the environment as a learning resource is environmental learning. This study aims to determine the effectiveness of environmental learning for students. The research method used is quantitative research methods. The data were obtained through a questionnaire distributed to 24 students of the Department of Science Education, Manado State University, who took part in environmental learning in the Biochemistry course. The data in this study were processed using a Likert scale calculation. The results showed that the students response index was obtained at intervals of $80 \%$ - 100\%, which means that the respondents strongly agreed that the environmental learning method was effective in motivating students to learn science.

\section{Keyword: Environmental learning}

\section{PENDAHULUAN}

Keadaan di lingkungan sekitar terkadang belum dimanfaatkan secara optimal dalam pembelajaran (Ichsan, Sigit, Miarsyah, 2019) sehingga kepedulian terhadap lingkungan belum disadari dengan baik. Seseorang yang peduli akan lingkungan dan paham akan pengetahuan adalah kunci untuk memelihara kelestarian lingkungan (Fujitani, McFall, Randler \& Arlinghaus, 2017). Pemanfaatan lingkungan sekitar adalah pemanfaatan segala sesuatu yang berada di lingkungan sekitar sebagai salah satu sumber belajar (Susanti, 2013). Penggunaan lingkungan sebagai salah satu sumber belajar dapat dijadikan sebagai objek yang menarik untuk dipelajari (Pantiwati, 2015).

Lingkungan sebagai sumber belajar memiliki peran penting sebagai bukti bahwa adanya interaksi antara manusia dengan alam sekitar. Pengetahuan akan adanya hubungan tersebut dapat dijadikan sebagai pembelajaran, sehingga pembelajaran tidak hanya melalui buku saja melainkan secara langsung dapat belajar dari lingkungan sekitar (Pasya, 2000). Belajar dengan menggunakan lingkungan sebagai sumber belajar dapat membantu siswa untuk menemukan hubungan yang bermakna antara konsep atau ide yang abstrak dengan penerapannya dalam kehidupan nyata melalui 
proses penemuan, pemberdayaan dan hubungan (Depdiknas dalam Uno \& Mohamad, 2011). Selain itu, belajar juga tidak hanya terbatas di dalam ruangan kelas saja akan tetapi dapat menjadikan lingkungan sebagai tempat belajar sehingga dapat menciptakan suasana belajar baru yang menyenangkan.

Environmental learning merupakan istilah yang dikaitkan dengan perubahan dalam pengetahuan, sikap dan perilaku individu terhadap lingkungan. Selain itu, individu yang berinteraksi dengan lingkungan atau masalah lingkungan dapat mencerminkan perubahan keterampilan dan rasa kepedulian terhadap lingkungan. Pada dasarnya, environmental learning dapat terjadi secara alami saat seseorang berinteraksi dengan lingkungan, atau dapat juga berlangsung dengan perencanaan dalam suatu pembelajaran formal yang disesuaikan dengan tujuan pembelajaran. (Barratt Hacking, Barratt \& Scott, 2007)

Environmental learning bukan hanya sebagai pembelajaran yang dilakukan dalam konteks pengetahuan seseorang terhadap masalah lingkungan, tetapi juga sebagai pengetahuan tentang bagaimana menangani masalah tersebut melalui tindakan dalam kehidupan sehari-hari (Robelia, Greenhow \& Burton, 2011). Environmental learning menekankan pada bagaimana individu memahami dan memaknai tentang alam, lingkungan, ekologi, serta masalah yang ada di lingkungan dengan pembelajaran secara mendalam, agar dapat dipahami dengan baik. Salah satu masalah dalam penerapan environmental learning yaitu kurangnya pemahaman tentang karakteristik dasar lingkungan yang menjadi sumber belajar. (Heimlich \& Horr, 2010)

Adapun masalah dalam lingkungan yang dapat kita temukan di lingkungan sekitar seperti masalah terkait pepohononan yang semakin lama semakin berkurang karena adanya penebangan secara sembarangan tanpa tahu akan dampak yang akan terjadi. Fungsi pohon diantaranya untuk menyimpan karbon dan meregulasi siklus air. Pohon juga mendukung sistem makanan alam dan manusia serta merupakan rumah bagi spesies yang ada di bumi termasuk bagi manusia dalam kegunaannya sebagai bahan bangunan. Akan tetapi, pohon sering ditebang hanya untuk keuntungan dalam hal ekonomi atau karena mengganggu pembangunan (Bbc.com, 2019). Dengan adanya penebangan pohon ini mengakibatkan masalah yang sering kita jumpai di kehidupan sehari-hari seperti suhu menjadi lebih panas serta terjadinya perubahan iklim yang tidak menentu (Lingkunganhidup.co., 2017).

Oleh karena itu, environmental learning diharapkan dapat meningkatkan kepedulian mahasiswa terhadap lingkungan sekitar dan peka terhadap masalah lingkungan yang terjadi di kehidupan sehari-hari. Adapun penelitian ini dilakukan dengan tujuan untuk mengetahui efektivitas environmental learning bagi mahasiswa.

\section{METODE PENELITIAN}

Metode penelitian yang digunakan dalam penelitian ini yaitu menggunakan metode penelitian kuantitatif. Penelitian ini dilakukan untuk melihat bagaimana efektivitas environmental learning bagi mahasiswa sehingga mahasiswa termotivasi untuk belajar IPA, dimana sampel dalam penelitian ini yaitu mahasiswa Jurusan Pendidikan IPA FMIPA Universitas Negeri Manado Semester IV sebanyak 24 orang yang mengontrak mata kuliah Biokimia. Pengumpulan data dilakukan dengan cara memberikan kuesioner kepada mahasiswa setelah melaksanakan pembelajaran IPA dengan metode environmental learning.

Alur penelitian ini diawali dengan menerapkan metode environmental learning dalam pembelajaran kemudian setelah melaksanakan pembelajaran dengan metode environmental learning, peneliti membagikan kuesioner melalui google form untuk mengukur efektivitas metode environmental learning yang telah dilakukan. Selanjutnya, hasil kuesioner ini dihitung berdasarkan perhitungan menggunakan Skala Likert.

Skala Likert digunakan untuk mengukur sikap, pendapat dan persepsi seseorang atau sekelompok mengenai suatu kejadian dengan menghubungkan setiap jawaban dengan 
pernyataan atau dukungan sikap yang diungkapkan dengan kata-kata (Riduwan, 2012).

Salah satu cara untuk menerjemahkan hasil skala likert adalah dengan analisis interval. Penggolongan skala jawaban pada skala Likert agar dapat dihitung secara kuantitatif, dapat dilihat pada Tabel 1 (Pranatawijaya, Widiatry, Priskila \& Putra, 2019).

Tabel 1. Penggolongan Skala Likert

\begin{tabular}{|c|c|c|}
\hline Kategori & $\begin{array}{c}\text { Bobot } \\
\text { Kategori }\end{array}$ & $\begin{array}{c}\text { Interval } \\
\text { Penilaian } \\
\text { Skor Akhir }\end{array}$ \\
\hline $\begin{array}{c}\text { Sangat Setuju } \\
\text { (SS) }\end{array}$ & 5 & $\begin{array}{c}80 \%- \\
100 \%\end{array}$ \\
\hline Setuju (S) & 4 & $\begin{array}{c}60 \%- \\
79,99 \%\end{array}$ \\
\hline Ragu-ragu (RR) & 3 & $\begin{array}{c}40 \%- \\
59,99 \%\end{array}$ \\
\hline Tidak Setuju (TS) & 2 & $\begin{array}{c}20 \%- \\
39,99 \%\end{array}$ \\
\hline Sangat Tidak \\
Setuju (STS) & 1 & $\begin{array}{c}0 \%- \\
19,99 \%\end{array}$ \\
\hline
\end{tabular}

\section{HASIL DAN PEMBAHASAN}

Berdasarkan pernyataan yang telah dibagikan dalam bentuk kuesioner, jawaban dari 24 responden disajikan melalui diagram batang pada Gambar 1.

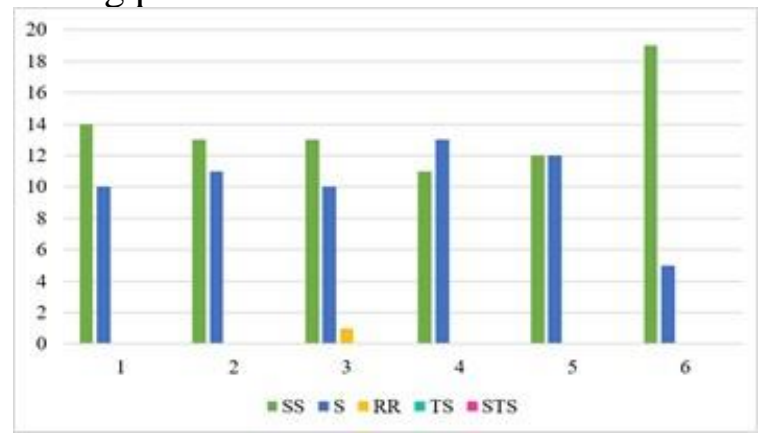

Gambar 1. Hasil Kuesioner

Berdasarkan data yang diperoleh pada Gambar 1, dapat dilihat bahwa jawaban responden dominan menjawab sangat setuju dan setuju untuk setiap item pertanyaan yang diberikan. Selanjutnya, hasil responden ini dihitung skornya dengan mengkalikan jumlah responden pada setiap jawaban dengan bobot setiap kategori yang telah ditentukan pada
Tabel 1. Sehingga diperoleh hasil yang dapat dilihat pada Tabel 2.

Tabel 2. Hasil Perhitungan Jawaban

Responden

\begin{tabular}{|c|c|c|c|c|c|c|}
\hline \multirow{2}{*}{ Item } & \multicolumn{5}{|c|}{ Skor Jawaban Responden } & \multirow{2}{*}{$\begin{array}{l}\text { Total } \\
\text { Skor }\end{array}$} \\
\hline & SS & $\mathrm{S}$ & $\mathrm{RR}$ & TS & STS & \\
\hline 1 & 70 & 40 & 0 & 0 & 0 & 110 \\
\hline 2 & 65 & 44 & 0 & 0 & 0 & 109 \\
\hline 3 & 65 & 40 & 3 & 0 & 0 & 108 \\
\hline 4 & 55 & 52 & 0 & 0 & 0 & 107 \\
\hline 5 & 60 & 48 & 0 & 0 & 0 & 108 \\
\hline 6 & 95 & 20 & 0 & 0 & 0 & 115 \\
\hline
\end{tabular}

Untuk mendapatkan hasil interpretasi dari kuesioner ini, harus diketahui terlebih dahulu skor maksimum dan minimum untuk item penilaian tertinggi dan terendah. Skor maksimum dihitung dengan mengkalikan jumlah responden dengan bobot tertinggi skala Likert (bobot 5) dan skor minimum dihitung dengan mengkalikan jumlah responden dengan bobot terrendah skala Likert (bobot 1). Bobot skala Likert dilihat berdasarkan Tabel 1. Sehingga, dapat dihitung skor maksimum item $\mathrm{SS}=24 \times 5=120$ dan skor minimum item $\mathrm{STS}=24 \times 1=24$.

Berdasarkan Tabel 2, hasil perhitungan jawaban kuesioner diinterpretasikan dengan menggunakan Rumus Indeks \% = Total Skor setiap item / skor maksimum item SS, yang hasilnya dapat dilihat pada Tabel 3.

Tabel 3. Hasil Interpretasi Jawaban Kuesioner

\begin{tabular}{|l|l|l|}
\hline Item & Indeks \% & Kategori \\
\hline 1 & 91,66 & Sangat Setuju \\
\hline 2 & 90,83 & Sangat Setuju \\
\hline 3 & 90,00 & Sangat Setuju \\
\hline 4 & 89,16 & Sangat Setuju \\
\hline 5 & 90,00 & Sangat Setuju \\
\hline 6 & 95,83 & Sangat Setuju \\
\hline
\end{tabular}

Berdasarkan Tabel 3, dapat dilihat bahwa setiap item memperoleh indeks dengan interval $80 \%-100 \%$ yang artinya responden Sangat Setuju bahwa metode environmental learning efektif untuk memotivasi mahasiswa dalam belajar IPA.

Pada dasarnya, environmental learning merupakan pembelajaran yang dilakukan dengan mendayagunakan lingkungan sebagai sumber belajar yang diharapkan dapat 
memberikan suasana menyenangkan serta memberikan pengalaman baru dalam pembelajaran (Wayan dalam Kahar, Ferny \& Meike, 2020). Hal ini bersesuaian dengan hasil penelitian ini bahwa penerapan metode environmental learning efektif untuk memotivasi mahasiswa dalam belajar IPA. Dimana, mahasiswa tertarik dengan kegiatan pembelajaran yang dilakukan di lingkungan sekitar, tertarik untuk mengamati lingkungan sekitar, merasa nyaman belajar di lingkungan sekitar, termotivasi dengan pembelajaran yang dilakukan di lingkungan, tertarik mengaitkan keadaan di lingkungan sekitar dengan pembelajaran dan lebih mudah memahami materi pembelajaran jika dikaitkan dengan lingkungan sekitar.

Oleh karena itu, dengan metode environmental learning mahasiswa dapat berinteraksi langsung dengan lingkungan sebagai sumber belajar dan menemukan sendiri masalah-masalah yang ada dilingkungan serta mencari solusi untuk menanggulangi masalah tersebut dalam kegunaannya di kehidupan sehari-hari. Selain itu, dengan environmental learning dapat tercipta suasana belajar yang baru dan menyenangkan sehingga dapat memotivasi siswa dalam belajar IPA serta menumbuhkan sikap kepedulian terhadap lingkungan.

Hal ini bersesuaian dengan penelitan sebelumnya yang menyatakan bahwa environmental learning dapat menarik perhatian peserta didik serta dapat meningkatkan aktivitas dan motivasi siswa dalam belajar, selain itu penggunaan lingkungan sebagai sumber belajar memungkinkan terjadinya pembelajaran yang lebih bermakna (Haryaningtyas, 2016). Selain itu, penelitian sebelumnya juga menyatakan bahwa environmental learning memiliki pengaruh terhadap peningkatan sikap peduli lingkungan peserta didik (Fitriati, Sahputra \& Lestari, 2019).

\section{KESIMPULAN}

Berdasarkan hasil penelitian dapat disimpulkan bahwa metode environmental learning efektif untuk memotivasi mahasiswa dalam belajar IPA.

\section{SARAN}

Penelitian ini dapat menjadi salah satu acuan bagi pendidik untuk memilih metode pembelajaran yang efektif dalam memotivasi peserta didik dalam belajar IPA, serta sebaiknya pendidik membiasakan untuk menerapkan environmental learning dalam pembelajaran dengan memanfaatkan lingkungan sekitar sebagai sumber belajar.

\section{DAFTAR PUSTAKA}

Barratt Hacking, E., Barratt, R., \& Scott, W. (2007). Engaging children: Research issues around participation and environmental learning. Environmental

Research, 13(4), 529-544.

Bbc.com. (2019, 11 September). What would happen if all the world's trees disappeared?. Diakses 15 November 2020, dari https://www.bbc.com/future/article/201909 11-what-would-happen-if-all-the-worldstrees-disappeared

Fitriati, M., Sahputra, R., \& Lestari, I. (2019). Pengaruh pembelajaran berbasis lingkungan terhadap sikap peduli lingkungan pada materi pencemaran lingkungan. Jurnal Pendidikan dan Pembelajaran Khatulistiwa, 8(1).

Fujitani, M., McFall, A., Randler, C., \& Arlinghaus, R. (2017). Participatory adaptive management leads to environmental learning outcomes extending beyond the sphere of science. Science Advances, 3(6), e1602516.

Haryaningtyas, H. (2016). Meningkatkan prestasi belajar IPA dan karakter peduli lingkungan melalui model pembelajaran environmental learning pada siswa kelas 7C SMPN 11 Madiun tahun pelajaran 2015/2016. Jurnal Penelitian LPPM (Lembaga Penelitian dan Pengabdian kepada Masyarakat) IKIP PGRI MADIUN, 4(2), 140-146.

Heimlich, J. E., \& Horr, E. E. T. (2010). Adult learning in free-choice, environmental settings: What makes it different?. New 
Directions for Adult and Continuing Education, 2010(127), 57-66.

Ichsan, I. Z., Sigit, D. V., \& Miarsyah, M. (2019). Environmental learning based on higher order thinking skills: a needs assessment. International Journal for Educational and Vocational Studies, 1(1), 21-24.

Kahar, S., Ferny T., \& Meike P. (2020). The effect of environmental learning models on science process skills and learning outcomes of students in SMP Negeri 10 Manado. International Journal of Academic Research and Development, 5(4), 34-38.

Lingkunganhidup.co. (2017, 28 Februari). Manfaat pohon bagi kehidupan manusia dan lingkungan. Diakses pada 15 November 2020, dari https://lingkunganhidup.co/manfaatpohon-bagi-manusia/

Pantiwati, Y. (2015). Pemanfaatan lingkungan sekolah sebagai sumber belajar dalam lesson study untuk meningkatkan metakognitif. Jurnal Bioedukatika, 3(1), 27-32.

Pasya, G. K. (2000). Lingkungan sebagai sumber belajar. Jurnal Pendidikan Ilmu Sosial (JPIS) No. 16. Halaman 28, Media Komunikasi Antar FPIPSUPI, FKIP Universitas/STKIP se-Indonesia.

Pranatawijaya, V. H., Widiatry, W., Priskila, R., \& Putra, P. B. A. A. (2019). Penerapan skala Likert dan skala Dikotomi pada kuesioner online. Jurnal Sains dan Informatika, 5(2), 128-137.

Riduwan, (2012). Skala pengukuran variabelvariabel penelitian. Bandung: Alfabeta.

Robelia, B. A., Greenhow, C., \& Burton, L. (2011). Environmental learning in online social networks: Adopting environmentally responsible behaviors. Environmental Education Research, 17(4), 553-575.

Susanti, N. D. (2013). Memanfaatkan lingkungan sekitar sebagai sumber belajar dengan tema lingkungan untuk meningkatkan hasil belajar siswa kelas III Sekolah Dasar. Jurnal Penelitian Pendidikan Guru Sekolah Dasar, 1(2), 111.
Uno, H. B., \& Mohamad, N. (2011). Belajar dengan pendekatan PAILKEM: pembelajaran, aktif, inovatif, lingkungan, kreatif, efektif, menarik. Jakarta: Bumi Aksara. 